\title{
Hemodialysis Adequacy: A Comparative Multicenter Study Between OCM and Calculated Kt/V from Two Centers in the Gulf
}

\section{Alaa A Sabry ${ }^{1 *}$, Khalid Alsaran², Ahmd Yehia' ${ }^{2}$, Eid M El-Shafey ${ }^{3}$ and Anas Al-Yousef ${ }^{4}$}

${ }^{1}$ Nephrology Division, Urology \& Nephrology Center, Mansoura University, Mansoura university, Egypt

${ }^{2}$ Prince Salman Center for Kidney Diseases, Riyadh, Kingdom of Saudi Arabia

IInternal Medicine Department, Faculty Of Medicine, Tanta University, Tanta, Egypt

${ }^{4}$ Nephrology Division, Internal Medicine Department, Jahra Hospital, Kuwait

\begin{abstract}
Introduction: Adequate delivered dose of solute removal (as assessed by urea reduction and calculation of Kt/V) is an important determinant of clinical outcome in chronic haemodialysis (HD) patients. This requires both prescription of an adequate dose of $\mathrm{HD}$ and regular assessment that the delivered treatments are also adequate. On line conductivity monitoring Kt/V OCM online clearance measurement (OCM) (OCM) -using sodium flux as a surrogate for urea- allows the repeated non-invasive measurement of $\mathrm{Kt} / \mathrm{V}$ on each $\mathrm{HD}$ treatment.
\end{abstract}

Methods: We prospectively studied 131 (63 males, 68 females) established chronic HD patients over 8 weeks period (1048 treatments). A pre and post dialyzer measurement of the conductivity is performed by two mutually independent temperature-compensated conductivity cells equipped with Fresenius $4008 \mathrm{~S}^{\circledR}$ dialysis machines. Urea reduction was measured (once a week) by a single pool calculation using immediate post treatment sampling. No changes were made to any of the dialysis prescriptions over the study period. Values of calculated Kt/V (conventional method with Daugirdas' formula) Kt/V Dau and simultaneously obtained online Kt/V OCM were compared.

Results: There was a statistically significant difference between calculated $\mathrm{Kt} / \mathrm{V} \mathrm{DAU}$ and $\mathrm{Kt} / \mathrm{V}$ OCM over the study period. The mean calculated Kt/V DAU was $1.459 \pm 0.31$, and mean OCM was $1.139 \pm 0.14(p=0.000)$, yet there was moderate correlation between calculated Kt/V DAU and Kt/V OCM $\left(r^{2}=0.59\right)(p=0.000)$ (Figure 1).

Conclusions: Online clearance measurement (OCM) results underestimates dialysis efficiency compared to calculated Kt/V DAU values. This difference has to be considered when applying Kt/V OCM to clinical practice (Figure 2).

Keywords: Kt/V; Hemodialysis; Online clearance monitoring

\section{Introduction}

Quantification of the dialysis dose is an essential element in the management of chronic haemodialysis treatment because the adequacy of the dose has a profound effect on patient morbidity and mortality [1]. The most useful and widely applied index to prescribe the dialysis dose (as well as to assess the dose which is actually delivered) is the $\mathrm{Kt} / \mathrm{V}$ DAU formula [1]. It is now well recognized that an adequate delivery of haemodialysis (HD) dose (as measured by Kt/V derived from urea reduction) is a crucial determinant in clinical outcome of chronic HD patients [2]. This requires both prescription of an adequate dose of HD and regular assessment that the delivered treatments are also adequate [3].

The greatest problem we are facing at the moment is to check whether the prescribed dialysis dose has actually been delivered. There is often a difference, sometimes large, between the prescribed and delivered dose [4].

There are many reasons why a discrepancy between calculated and delivered dose of extra-corporeal blood purification might exist. Failure of staff to ensure the pre-determined treatment time is given (usually in the face of variable patient resistance) is a common failing. However, other factors such as suboptimal needle placement, haemodynamic instability and progressive access malfunction all militate against this optimal delivery [5]. Bed-side $\mathrm{Kt} / \mathrm{V}$ is currently determined using various kinetic models; the most widely used being the single-pool variable volume urea kinetic model (SPVV- UKM) [6].

The European Best Practice Guidelines recommended as minimum treatment dose an equilibrated $\mathrm{Kt} / \mathrm{V}=1.2$ [7], but in clinical practice this value cannot be achieved for every patient [8]. According to the guidelines, dialysis dose should be measured using a validated method
[7]. Apart from blood sample-based methods, alternative methods determining dialysis dose have been developed, mostly based on measurements of conductivity [9] or of urea [10], recently also of ultraviolet absorbance in the spent dialysate [11].

On-line clearance monitors measure the difference in conductivity between the dialysate entering and leaving the dialyser with two different dialysate inlet electrolyte concentrations [12].

On-line clearance monitoring (OCM) allows dialysis dose to be monitored at every treatment with virtually no additional overheads. While it is unlikely that these non-invasive measurements of $K t / V$ will replace routine blood sampling, OCM affords staff the opportunity to monitor unstable patients more effectively, identify problems quickly and assess the effect of remedial actions.

Recently, advances in the on-line monitoring of conductivity during $\mathrm{HD}$ sessions have made the repeated measurement of $\mathrm{Kt} / \mathrm{V}$ OCM on all HD treatment sessions a practical proposition [13]. This method has been shown to have an excellent correlation with $\mathrm{Kt} / \mathrm{V}$

*Corresponding author: Alaa Sabry, Assistant Professor of Nephrology, Mansoura Urology and Nephrology Center, Mansoura University, Egypt, Tel: 002-050-2524024; Fax: 002-050-226-3717; E-mail: asabry2040@yahoo.com

Received August 08, 2011; Accepted December 16, 2011; Published Decembe 18, 2011

Citation: Sabry AA, Alsaran K, Yehia A, El-Shafey EM, Al-Yousef A (2011) Hemodialysis Adequacy: A Comparative Multicenter Study Between OCM and Calculated Kt/V from Two Centers in the Gulf. J Nephrol Therapeutic 1:108 doi:10.4172/2161-0959.1000108

Copyright: () 2011 Sabry AA, et al. This is an open-access article distributed under the terms of the Creative Commons Attribution License, which permits unrestricted use, distribution, and reproduction in any medium, provided the original author and source are credited. 
measured by urea reduction in a number of small studies [14-15]. However other studies reveal that OCM underestimate dialysis efficacy when compared with calculated Kt/V [16-17].

In view of these contradictory results, the aim of this prospective clinical trial was the comparison over a wide range of dialysis doses of the two methods, Kt/V Dau, Kt/V OCM to test the validity of ionic dialysance in determining $\mathrm{Kt} / \mathrm{V}$ in comparison with the gold standard direct quantification method using the single-pool variable volume urea kinetic model (SPVV- UKM) in a series of haemodialysis patients from 2 centers in the gulf area.

\section{Subjects and Methods}

\section{Patients}

Demographic criteria: We prospectively studied 131 patients (63 males, 68 females) chronic HD patients over 8 weeks (1048 treatments) (Table 1). All patients had been on HD for $>3$ months (mean $32.13 \pm$ 32.57 months). Patients were allocated from 2 dialysis centers; Princa Salman Center for Kidney Diseases located in Riyadh- the capital of Saudi Arabia and Nephrology unit, Internal Medicine Department, Jahra Hospital, Kuwait.

Dialysis prescription: All our patients were on Hemoflow PnSeries High - Flux (Fresenius polysulphone Capillary dialysers - Pn60 LS and Pn80S), 77 of them were dialyzing via AVF while 45 were dialyzing via permicath and 9 via AVG. Patients received dialysis with Fresenius $4008 \mathrm{~S}$ monitors equipped with OCM biosensors (On-line clearance monitoring, Fresenius Medical Care AG). Mean age was 51.5

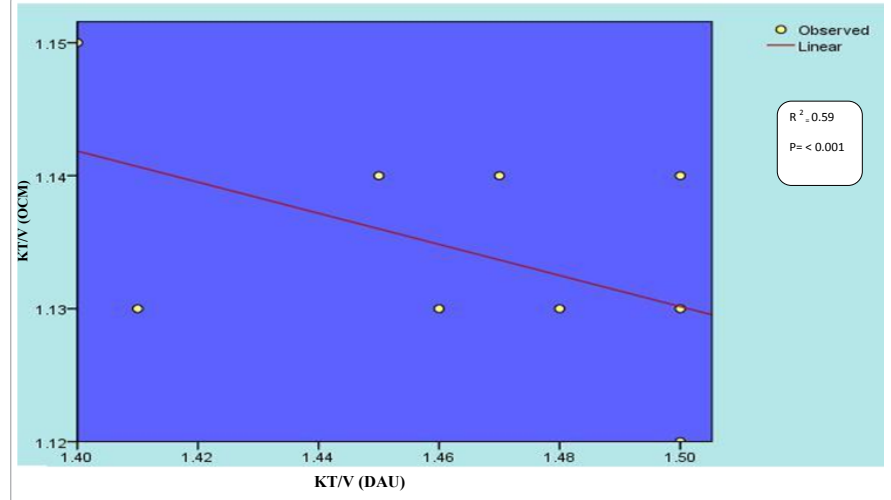

Figure 1: Correlation between $\mathrm{Kt} / \mathrm{V}$ as measured by urea reduction and by ionic dialysance over the study period.

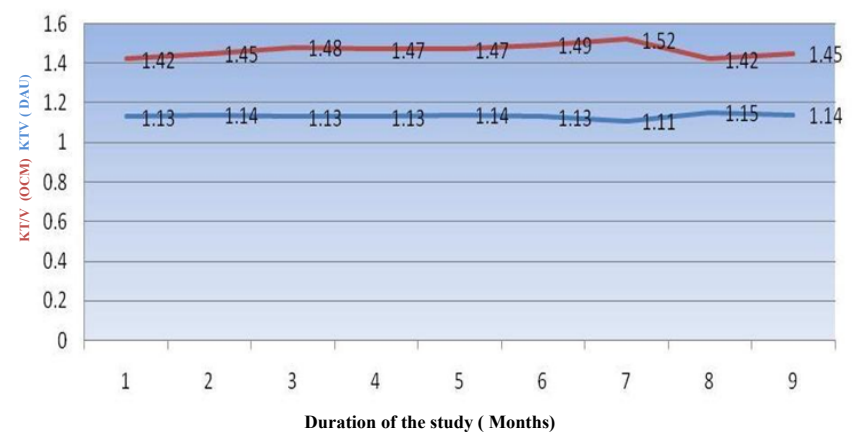

Figure 2: Comparison between $\mathrm{KT} / \mathrm{V}(\mathrm{OCM})$ and $\mathrm{KT} / \mathrm{V}(\mathrm{DAU})$ over the study period.

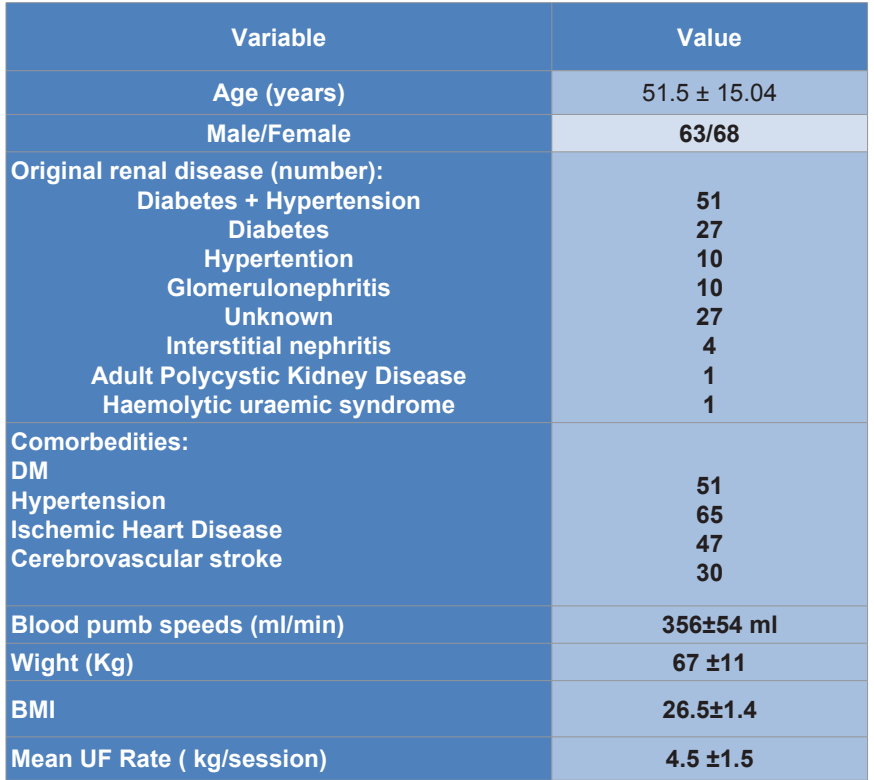

Table 1: Demographic criteria for 131 patients included in our study.

years $( \pm 15.04$ years), fifty percent of our patients had blood flow rate was $300 \mathrm{ml} / \mathrm{min}$ (range 200-300 $\mathrm{ml} / \mathrm{min}$ ), The mean treatment time was $180 \mathrm{~min}$ (range 150-210), and the dialysate flow was fixed at $500 \mathrm{ml} /$ min.No changes were made to any of the dialysis prescriptions over the study period.

\section{Measurement of dialysis adequacy}

$\mathrm{Kt} / \mathrm{V}$ was measured by two techniques. The first method is the conventional method with blood sampling and calculation (Kt/V Dau). The second technique is effective plasma conductivity that is performed by two mutually independent temperature-compensated conductivity cells equipped with Fresenius $4008 \mathrm{~S}^{\circledast}$ dialysis machines $\left(\mathrm{Kt} / \mathrm{V}_{\mathrm{ID}}\right)$. The Fresenius module changes inlet conductivity every $30 \mathrm{~min}$ and records the change in conductivity at a second conductance meter at the dialysate waste. From this change ionic dialysance and plasma conductivity can be calculated automatically. Because the transfer characteristics of sodium and urea are similar, the ionic dialysance reflects the clearance of urea. For each patient and each dialytic session, $\mathrm{Kt} / \mathrm{V}_{\mathrm{ID}}$ is calculated automatically by the dialysis monitor. Total body water, which is assumed to be equal to urea distribution volume, was calculated by the dialysis machine using the empirical formula of Watson et al. [18] for women and men, respectively.

The Research Ethics Board in the 2 centers approved the study protocol and a written consent was signed from all participants.

\section{Statistical analysis}

The values of Kt/V by each of the two methods are expressed as means \pm standard deviation. A $\mathrm{P}$ value of $\leq 0.05$ was considered significant. The Spearman correlation test was used to assess the relationship between the two exploratory methods and the Student's $t$ test to compare the results obtained by the Kt/V DAU and Kt/V OCM. All data were analyzed using the SPSS for windows software package release 17.

\section{Results}

\section{Patients' characteristics}

Our study included 131 patients (63 males, 68 females); their mean 
age was (51.5 \pm 15.04 years), mean dialysis duration was $32.13 \pm 32.57$ months.

\section{Dialysis prescription}

More than $58.8 \%$ of our patients were using AVF, about $34.4 \%$ only were using permicath and the remaining was using AVG.

\section{Comparison between $\mathrm{Kt} / \mathrm{V}$ obtained by the two methods}

Mean $\mathrm{Kt} / \mathrm{V}$ was $(1.459 \pm 0.31)$ as measured by the single-pool variable volume urea kinetic model (KT/V DAU) while it was (1.139 \pm $0.14)$ as measured by ionic dialysance (OCM). The difference between these two values did reach a statistical significance $(P=0.000)$.

\section{Correlation analysis}

This was performed between all obtained online Kt/V DAU and $\mathrm{Kt} / \mathrm{V}$ OCM. Two values of online $\mathrm{Kt} / \mathrm{V}$ were used for correlation: simultaneous $\mathrm{Kt} / \mathrm{V}$, taken at the same time when OCM measurements were performed, and mean $\mathrm{Kt} / \mathrm{V}$ representing the mean $\mathrm{Kt} / \mathrm{V}$ value for both methods. There was positive correlation between calculated Kt/V and online $\mathrm{Kt} / \mathrm{V}\left(\mathrm{r}^{2}=0.59\right)$ with $(\mathrm{P}=0.001)$.

\section{Discussion}

Dialysis dose quantification by means of $\mathrm{Kt} / \mathrm{V}$ is of fundamental importance in prescribing and, above all, assessing the adequacy of the dialysis actually delivered, which is strictly related to patient morbidity and mortality. The direct quantification of removed urea (the gold standard for determining $\mathrm{Kt} / \mathrm{V}$ ) cannot be used on a routine basis since it requires the total or partial collection of spent dialysate; and on-line urea sensing devices are too expensive to be a real alternative at the moment [19]. It is well known that the difference between prescribed and delivered dialysis doses greatly affects the morbidity and mortality of dialysed patients. The on-line monitoring of delivered dialysis is therefore of paramount importance. Kt/V is usually calculated monthly from pre- and post dialysis blood samples. A number of factors lead to a lower delivered dose than prescribed, such as cardiopulmonary and access recirculation, compartmental disequilibrium, loss in dialyzer clearance, and actual values of blood flow or effective treatment time being less than prescribed. If $\mathrm{Kt} / \mathrm{V}$ is measured once per month, important variations in delivered dialysis dose may be missed. Measurement of delivered dialysis dose each dialysis would be desirable if it could be achieved without blood samples [19]. It is therefore not surprising that great interest should be shown in a method which can allow Kt/V to be determined at each session without the need for any blood or dialysate samples, and at no additional cost [20].

The ability to assess Kt/V on each treatment also gives some insight into the significant variability of delivered dose that each individual patient is subjected to [16]. In our study a correlation coefficient between $\mathrm{Kt} / \mathrm{V}$ obtained online and calculated as SPVV Kt/V with urea measurement in blood probes was about 0.59 . This is in agreement with that was reported by Grzegorzewska AE et al. [17]. Who studied 40 patients with total number of sessions involved in his study were 80 for each method, while in our study we included 131 patients with total number of 1048 records for each method.

Results of McIntyre et al. [16] indicate that the significantly greater correlation coefficient between values of SPVV urea Kt/V and online $\mathrm{Kt} / \mathrm{V}$ can be obtained, when blood sample for urea determination is drawn 30 minutes after the end of the HD session $(\mathrm{R} 2=0.92, \mathrm{p}<$ 0.001). But this double-pool measurement of $\mathrm{Kt} / \mathrm{V}$ is not practical due to difficulty in compliance and inconvenience for many patients. There is indirect evidence to suggest that there may actually be a difference between the two parameters. It has been observed that the value of ionic dialysance can decrease during dialytic sessions performed using a high ultrafiltration rate, and a correlation has been found between the decrease in ionic dialysance and the decrease in plasma water flow at a constant blood flow, On the contrary, no decrease in effective urea clearance has been observed, and blood water flow (the solvent for urea) is not significantly reduced by intradialytic ultrafiltration. Consequently, although the urea and sodium diffusion constants are almost equal, ionic dialysance cannot be assimilated to urea clearance because of the difference in effective blood flow, which is lower for ionic dialysance and mainly represented by plasma water flow [21].

For explanation of only moderate correlation between online $\mathrm{Kt} / \mathrm{V}$ and $\mathrm{Kt} / \mathrm{V}$ obtained using urea estimations these points should be considered, The whole spent dialysate was not collected in our study, Unlike what is reported by Petitclerc et al. [22] where the whole spent dialysate was collected and used for Kt/V measurement, which could explain a higher correlation coefficient, showing value of 0.94 . Collection of the whole spent dialysate is very inconvenient. For this reason, collection of a representative fraction of spent hemodialysate [23], continuous sampling of spent dialysate and total dialysate volume measurement [23] or dialysate sampling at the beginning and at the end of dialysis session [24] were advised. These methods did not find, however, a place in routine clinical practice. And according to the European best practice guidelines on hemodialysis, online clearance should not substitute for monthly measurements using the reference method (equilibrated $\mathrm{Kt} / \mathrm{V}$ ), but it is an acceptable method for calculating haemodialysis on a treatment-by-treatment basis [25]. There are many advantage for OCM technique, First an automatic measurement of the dialysis dose during every dialysis session does no harm to the patient, as no blood samples are taken. For patients with a constant dialysis dose. Second the benefit of an automatic measurement may be moderate, but for patients with varying and lower dialysis doses the risk of an undetected low dialysis dose for longer periods of time are real, and the benefit of continuous surveillance concerning dose delivery seems obvious.

In conclusion, our study show that $\mathrm{Kt} / \mathrm{V}$ obtained using online monitoring indicates a lower intermittent haemodialysis adequacy than those calculated from urea measurements. So they cannot replace each other without proper correction. Nevertheless the close correlation between the two parameters makes it easy to derive effective urea clearance from ionic dialysance. Since it is reasonable to assume that urea distribution volume is constant in steady-state patients, once this has been exactly determined by means of the measurement of ionic dialysance, it is possible to calculate $\mathrm{Kt} / \mathrm{V}$ on-line at each session without the need for any blood sampling or laboratory examinations, and at no additional cost.

\section{References}

1. Gotch FA, Sargent JA (1985) A mechanistic analysis of the National Cooperative Dialysis Study (NCDS). Kidney Int 28: 526-534.

2. Woods J, Port F, Stannard D, Blagg C, Held P (1996) Comparison of mortality with home hemodialysis and center hemodialysis: a national study. Kidney Int 49: 1464-1470.

3. Kloppenburg WD, Stegeman CA, Hooyschuur M, van der Ven J, de Jong PE, et al. (1999) Assessing dialysis adequacy and dietary intake in the individual hemodialysis patient. Kidney Int 55: 1961-1969.

4. Held PJ, Port FK, Garcia J, Gaylin DS, Levin NW, et al. (1991) Hemodialysis prescription and delivery in the US: Results from USRDS case mix study. J Am Soc Nephrol 2: 238. 
Citation: Sabry AA, Alsaran K, Yehia A, El-Shafey EM, Al-Yousef A (2011) Hemodialysis Adequacy: A Comparative Multicenter Study Between OCM and Calculated Kt/V from Two Centers in the Gulf. J Nephrol Therapeutic 1:108. doi:10.4172/2161-0959.1000108

5. K-DOQI Clinical Practice Guidelines for Hemodialysis Adequacy (2001) Hemodialysis dose troubleshooting. Am J Kidney Dis 37: 179-194.

6. Sargent JA, Gotch FA (1983) Principles and biophysics of dialysis. In: Dmkker W, Parsons FM, Maher JF, eds. Replacement of Renal Function bv Dialysis. Martinus Nijhoff, Boston, 53-96.

7. European Best Practice Guidelines for Hemodialysis: Part 1. Nephrol Dial Transplant 17: 16-31.

8. Press MH, Benz RL (2006) Quantifying the role of factors that limit attainment of K/DOQI urea reduction ratio dialytic goal. Clin Nephrol 66: 98-102.

9. Racki S, Zaputović L, Maleta I, Grzetić M, Mavrić Z, et al. (2005) Assessment of hemodialysis adequacy by ionic dialysance: comparison to standard method of urea removal. Ren Fail 27: 601-604.

10. Sternby J (1999) Urea sensors - a world of possibilities. Adv Ren Replace Ther 6: 265-272.

11. Castellarnau A, Werner M, Günthner R, Jakob M (1993) Real-time Kt/M determination by ultraviolet absorbance in spent dialysate: technique validation. Kidney Int 78: 920-925

12. Polaschegg HD (1993) Automatic, noninvasive intradialytic clearance measurement. Int J Artif Organs 16:185-191.

13. Mercadal L, Petitclerc T, Jaudon M, Bene B, Goux N, et al. (1998) Is ionic dialysance a valid parameter for quantification of dialysis efficiency?. Artif Organs 22: 1005-1009.

14. Lindsay RM, Bene B, Goux N, Heidenheim AP, Landgren C, et al. (2001) Relationship between effective ionic dialysance and in vivo urea clearance during haemodialysis. Am J Kidney Dis 38: 565-574.

15. Teruel JL, Fernández Lucas M, Marcén R, Rodríguez JR, Rivera M, et al. (2001) Estimate of dialysis dose using ionic dialysance. Nefrologia 1: 78-83.
16. Mclntyre CW, Lambie SH, Taal MW, Fluck RJ (2003) Assessment of haemodialysis adequacy by ionic dialysance: intra-patient variability of delivered treatment. Nephrol Dial Transplant 18: 559-563.

17. Grzegorzewska AE, Banachowicz W (2008) Evaluation of haemodialysis adequacy using online $\mathrm{Kt} / \mathrm{V}$ and single-pool variable-volume urea $\mathrm{Kt} / \mathrm{V}$. Int Uro Nephrol 40:771-778

18. Watson PE, Watson ID, Batt RD (1980) Total body water volumes for adult males and females estimated from simple anthropometric measurements. Am J Clin Nutr 33: 27-39.

19. Daugirdas JT (1993) Second generation logarithmic estimates of single poo variable volume KtuV: an analysis of error. J Am Soc Nephrol 4: 1205-1213.

20. Manzoni C, Di Filippo S, Corti M, Locatelli F (1996) lonic dialysance as a method for the on - line monitoring of delivered dialysis without blood sampling Nephrol Dial Transplant 11: 2023-2030.

21. Sargent JA, Gotch FA (1983) Principles and biophysics of dialysis. In: Dmkke W, Parsons FM, Maher JF, eds. Replacement of Renal Function bv Dialysis. Martinus Nijhoff, Boston, 53-96

22. Petitclerc T, Béné B, Jacobs C, Jaudon MC, Goux N (1995) Non-invasive monitoring of effective dialysis dose delivered to the haemodialysis patient. Nephrol Dial Transplant 10: 212-216.

23. Argilés A, Ficheux A, Thomas M, Bosc JY, Kerr PG, et al. (1997) Precise quantification of dialysis using continuous sampling of spent dialysate and total dialysate volume measurement. Kidney Int 52: 530-537.

24. Raj DS, Tobe S, Saiphoo C, Manuel MA (1997) Quantitating dialysis using two dialysate samples: a simple, practical and accurate approach for evaluating urea kinetics. Int J Artif Organs 20: 422-427.

25. European best practice guidelines on haemodialysis (2007) Nephrol Dia Transplant 22: 16-21. 